\title{
Bartonella spp. seroprevalence in tick-exposed Swedish patients with persistent symptoms
}

\author{
Marie Edvinsson ${ }^{1 *} \mathbb{D}$, Camilla Norlander ${ }^{1}$, Kenneth Nilsson ${ }^{1,2}$, Andreas Mårtensson ${ }^{3}$, Elisabet Skoog ${ }^{1}$ and \\ Björn Olsen ${ }^{1}$
}

\begin{abstract}
Background: Bartonella spp. are emerging pathogens transmitted by arthropod vectors, possibly including ticks. We have investigated signs of bartonellosis in Swedish patients with presumed tick-bite exposure and symptom duration of at least 6 months.

Methods: Serological testing for Bartonella henselae and Bartonella quintana was performed in 224 patients. Symptoms, tick exposure, evidence of co-infection and previous treatments were evaluated. Seropositive patients were compared to a matched group (twofold larger and negative serology) from the same study cohort.

Results: Seroprevalence was $7 \%$ for B. henselae and $1 \%$ for B. quintana, with one patient testing positive to both agents. Tick bites were reported by $63 \%$ of the patients in the seropositive group and $88 \%$ in the seronegative group and presumed tick exposure was more common in the seronegative group. Animal contact was equally common in both groups, along with reported symptoms. The most common symptoms were fatigue, muscular symptoms, arthralgia and cognitive symptoms. Exposure to co-infections was evenly distributed in the seropositive and seronegative groups.

Conclusions: Antibodies to Bartonella were more common in this cohort of patients than in cohorts of healthy Swedish blood donors in previous studies but lower than those in blood donors from southern Europe. Positive Bartonella serology was not linked to any specific symptom, nor to (suspected) tick-bite exposure.
\end{abstract}

Keywords: Bartonella, Ticks, Vector-borne disease

\section{Background}

Bartonella spp. are slow-growing facultative intracellular bacteria that may cause various diseases, both in humans and animals. These zoonotic bacteria can be transmitted directly from animals to humans (e.g. Bartonella henselae) or by different blood-sucking vectors, including lice and flies. More than 40 Bartonella spp. are known at the present time, among which at least 14 are considered to

*Correspondence: marie.edvinsson@medsci.uu.se

${ }^{1}$ Department of Medical Sciences, Section of Infectious Diseases, Uppsala University, Uppsala, Sweden

Full list of author information is available at the end of the article be human pathogens $[1,2]$. Most infections in humans are caused by Bartonella quintana, $B$. henselae and Bartonella bacilliformis [2], with B. bacilliformis being endemic to the Andes mountains of South America.

The Bartonella bacterium may invade and persist in red blood cells and endothelial cells and then be transferred by different arthropod vectors [3]. Ticks have been proposed, but not confirmed, as a vector for Bartonella transmission [4-6]. Different Bartonella spp. have been demonstrated in Ixodes ricinus ticks [7, 8], which is the tick species most often affecting humans and other large- and medium-sized animals in Sweden original author(s) and the source, provide a link to the Creative Commons licence, and indicate if changes were made. The images or other third party material in this article are included in the article's Creative Commons licence, unless indicated otherwise in a credit line to the material. If material is not included in the article's Creative Commons licence and your intended use is not permitted by statutory regulation or exceeds the permitted use, you will need to obtain permission directly from the copyright holder. To view a copy of this licence, visit http://creativecommons.org/licenses/by/4.0/. The Creative Commons Public Domain Dedication waiver (http://creativeco mmons.org/publicdomain/zero/1.0/) applies to the data made available in this article, unless otherwise stated in a credit line to the data. 
and Europe [9]. This tick is also the vector for Borrelia burgdorferi $[9,10]$, and co-infections in ticks have been demonstrated, a phenomenon that may result in the transmission of more than one pathogen during a tick bite $[5,11,12]$. Bartonella henselae and other Bartonella spp. have been demonstrated in the blood of patients exposed to ticks [13].

Human bartonellosis can present with a wide range of symptoms and diseases [14-17]. For example, B. quintana is the cause of trench fever with recurring fever, headache and bone pain [18], and B. henselae may cause cat-scratch disease with lymphadenopathy, fever and myalgia [19]. Atypical presentations of cat-scratch disease have also been reported with neurological and/ or rheumatological symptoms [19-21]. Both B. quintana and $B$. henselae may cause endocarditis. Other Bartonella spp. have also been reported as the cause of endocarditis in a few patients [4]. Moreover, asymptomatic bacteremia with Bartonella spp. has been demonstrated in humans [22] and animals [7].

Patients suffering from persistent unexplained symptoms sometimes attribute these to a previous tick bite [23]. If Bartonella spp. are transmitted by ticks, an investigation for Bartonella infection may be relevant in this patient population. Therefore, we examined a cohort of Swedish patients with suspected previous tick exposure for the prevalence of antibodies against $B$. henselae and B. quintana and analyzed their epidemiological, clinical and baseline demographic data compared to a group of seronegative patients attending the same clinic.

\section{Methods}

\section{Study population}

We purposely selected participants from an exploratory study of human tick-borne infections conducted at the Center for Vector-borne Infections (CVI), Uppsala University Hospital, Uppsala, Sweden between October 2015 and December 2018 [24]. A total of 224 patients were enrolled in the principal study during this period. All patients completed standardized questionnaires on their symptoms and tick exposure and underwent a standardized medical and laboratory examination at the outpatient clinic. Patients had to fulfill at least four of seven predefined inclusion criteria of which symptom duration of $>6$ months was mandatory. The other criteria were age $\geq 18$ years; suspected tick-borne infection based on previous tick exposure; symptoms; laboratory findings; previous treatment for tick-borne infection; and/or suspicion of co-infection with other tick-borne infections. A summary of data on these patients has previously been published [24].

\section{Bartonella serology}

Patient sera were analyzed as part of routine diagnostics at the Uppsala University Hospital, Uppsala, Sweden for IgG antibodies against $B$. henselae and $B$. quintana by indirect immunofluorescence assay (IFA) using the Anti-Bartonella henselae/quintana IIFT Mosaic kit from Euroimmun AG (Lübeck, Germany) according to the manufacturer's instructions. Titers at 1:64 were considered to be the limit value for $B$. henselae and B. quintana and titers at 1:128 or higher were considered to indicate seropositivity. Positive samples were titrated to end titer.

\section{Microbiological testing}

All patients were also examined for other tick-borne infections known to be present in Sweden, such as serological testing for Borrelia burgdorferi, Borrelia afzelii and Borrelia garinii (Euroimmun ${ }^{\circledR}$, Lübeck, Germany) and Anaplasma phagocytophilum (Focus Diagnostics ${ }^{\circledR}$, Cypress, CA, USA). Serological tests (IFA) for antibodies against Babesia microti and Babesia divergens were performed at the Public Health Agency of Sweden, Solna, Stockholm and the National Institute for Public Health and the Environment (RIVM), Bilthoven, the Netherlands. Serological testing (IFA) and PCR assays for Rickettsia spp. and tick-borne encephalitis virus (Immunozym FSME IgM and IgG, respectively; Progen Biotechnik GmbH, Heidelberg, Germany) and the PCR assay for Candidatus Neoehrlichia mikurensis in blood were performed at Sahlgrenska University Hospital, Gothenburg, Sweden as previously described [24].

\section{Statistical analysis}

The Chi-square test and Fisher's exact test were conducted using IBM SPSS Statistics (SPSS, IBM Corp., Armonk, NY, USA).

\section{Results}

\section{Patient demographics}

The study included 224 patients, of whom 16 (7\%) were seropositive for antibodies against $B$. quintana or B. henselae, or both. An anti-Bartonella spp. IgGseronegative group of 32 patients was matched for age, sex and region of residence from the same cohort of patients investigated at the CVI. The seropositive group included 10 women and six men with a mean age of 57 (range 23-77) years; the seronegative group comprised 20 women and 12 men with a mean age of 56 (range 20-80) years. Most patients in both groups (88\%) were from central Sweden, with the majority (69\% of all patients) from the region of Uppsala and Stockholm. The 
remaining patients were from the southern part of Sweden; none came from the northern region of Sweden.

\section{Bartonella serology}

Sixteen patients (7\%) were seropositive: 14 against $B$. henselae, one against $B$. quintana and one against both $B$. henselae and B. quintana. Anti-Bartonella IgG titers against $B$. quintana were between 1:64 and 1:512. The patient with the highest titer was also seropositive for $B$. henselae (titer: 1:64). For $B$. henselae, nine patients had a titer of 1:64; four, 1:128; one, 1:256; and one, 1:512. Seroprevalence was $7 \%$ for $B$. henselae and $1 \%$ for B. quintana in the investigated cohort.

\section{Co-infections}

The search for other tick-borne pathogens revealed a possible infection with Candidatus Neoehrlichia mikurensis in one of the Bartonella-seropositive patients. Previous exposure to, but no ongoing infection of B. burgdorferi, A. phagocytophilum and Rickettsia spp. was demonstrated. The number of patients in each group is listed in Table 1. None of the patients had signs of previous exposure to or ongoing infection with tick-borne encephalitis virus, $B$. divergens or $B$. microti. There was no difference between the groups in the number of patients with previous exposure to tick-borne pathogens.

\section{Tick-exposure}

Epidemiological factors related to tick exposure are shown in Table 2. Most patients who were either seropositive or seronegative for Bartonella reported tick bites approximately once per year. Although the difference was not statistically significant, the frequency of tick bites tended to be higher in seronegative patients. Furthermore, when the prevalence of tick bites was investigated in all anti-Bartonella spp. IgG-negative patients in the entire cohort investigated at the CVI clinic $(n=208), 79 \%$ reported tick bites. All participants in the present study reported that they walked in woods and fields over the years. Patients in the seronegative group reported berry picking $(P=0.012)$ and being on a boat or in the archipelago $(P=0.005)$ more frequently than patients in the seropositive group. When we looked at tick exposure only in the group of patients with a titer > 1:64 (i.e. 7 patients) and compared these patients to the seronegative group, we found was no difference in terms of the factors related to tick exposure. Travel history was not assessed due to incomplete or missing information on this variable from the patients.

Table 1 Number of patients with previous exposure to tick-borne pathogens

\begin{tabular}{llc}
\hline Exposure to a pathogen & $\begin{array}{l}\text { Patients positive for anti-Bartonella spp. IgG } \\
\text { antibodies }(n=16)\end{array}$ & $\begin{array}{l}\text { Patients negative for anti- } \\
\text { Bartonella spp. IgG antibodies } \\
(n=32)\end{array}$ \\
\hline Borrelia burgdorferi sensu lato lgM/lgG & $11(69 \%)$ & $21(66 \%)$ \\
Anaplasma phagocytophilum IgG & $2(13 \%)$ & $6(19 \%)$ \\
Rickettsia spp. IgG & $5(31 \%)$ & $8(25 \%)$ \\
Candidatus Neoehrlichia mikurensis PCR & $1(6 \%)$ & $0(0 \%)$
\end{tabular}

Table 2 Epidemiological factors related to tick exposure in Bartonella-seropositive and -seronegative patients

\begin{tabular}{lcc}
\hline Epidemiological factors & $\begin{array}{l}\text { Patients positive for anti-Bartonella spp. IgG antibodies } \\
(n=16)\end{array}$ & $\begin{array}{l}\text { Patients negative for anti- } \\
\text { Bartonella spp. lgG antibodies } \\
(n=32)\end{array}$ \\
\hline Walking In woods or fields & $15(94 \%)$ & $32(100 \%)$ \\
Gardening & $10(63 \%)$ & $28(88 \%)$ \\
Tick bite & $10(63 \%)$ & $28(88 \%)$ \\
Berry picking & $5(31 \%)$ & $23(72 \%)$ \\
Boat/archipelago & $5(31 \%)$ & $24(75 \%)$ \\
Hunting & $2(13 \%)$ & $4(13 \%)$ \\
Golf & $1(6 \%)$ & $2(6 \%)$ \\
Pet animal(s) & $7(44 \%)$ & $15(47 \%)$ \\
Dog(s) & $5(31 \%)$ & $9(28 \%)$ \\
Cat(s) & $2(13 \%)$ & $8(25 \%)$ \\
Horse(s) & $2(13 \%)$ & $2(6.3 \%)$ \\
\hline
\end{tabular}




\section{Symptoms}

Reported symptoms in Bartonella-seropositive and -seronegative patients are listed in Table 3. The most frequently reported symptoms in the seropositive group were fatigue, muscular symptoms, arthralgia and sleeping problems. Muscular symptoms included muscle pain, spasms, muscle weakness and cramps, while sleeping problems included insomnia, prolonged sleep duration and daytime sleeping. In the seronegative group, fatigue was also a common symptom. Both the seropositive and negative groups rated fatigue as severe. In the seronegative group cognitive symptoms (e.g. confusion, concentration difficulties, difficulty processing new information, searching for names, forgetfulness, disorientation and dysphasia) were the most common symptoms. In three of the patients with previous Bell's palsy, the serological testing of the cerebrospinal fluid was positive for Borrelia, which was interpreted as previous neuroborreliosis. There was no significant statistical difference between the two groups in terms of symptoms. Comparison of the symptoms in the group of patients with a positive antiBartonella spp. IgG titer $>1: 64$ (i.e. 7 patients) to those of the seronegative group revealed that cognitive symptoms were more common $(P=0.022)$ in the seronegative group. However, this finding should be considered uncertain due to the small size of the groups.

\section{Antibiotic treatment}

Previous antibiotic treatment in Bartonella-seropositive and Bartonella-seronegative patients is shown in Table 4. Three patients had been treated with $\geq 2$ different antibiotics and three patients reported $\geq 2$ courses of treatment with the same sort of antibiotics. Doxycycline was the most commonly used antibiotic, reported by $38 \%$ in the seropositive and $28 \%$ in the seronegative group. All other antibiotics were reported only by very few patients. Two patients in the Bartonella-seropositive group were recommended doxycycline treatment; one patient was positive for Candidatus Neoehrlichia mikurensis in the blood and had a titer against $B$. henselae of $1: 128$, and the other patient had a titer of 1:256 against $B$. henselae that persisted during follow-up 2 months later. These findings together with long-lasting diffuse symptoms and no previous treatment with antibiotics effective against Bartonella infection resulted in the recommended treatment.

Table 3 Reported symptoms in Bartonella-seropositive and Bartonella-seronegative patients

\begin{tabular}{|c|c|c|c|}
\hline Symptoms & $\begin{array}{l}\text { Patients positive for anti-Bartonella spp. } \\
\text { lgG antibodies }(n=16)\end{array}$ & $\begin{array}{l}\text { Patients negative for anti-Bartonella } \\
\text { spp. IgG antibodies }(n=32)\end{array}$ & Total $(n=48)$ \\
\hline Fatigue & 15 (94\%) & $27(84 \%)$ & $42(88 \%)$ \\
\hline Sleeping problems & $11(69 \%)$ & $25(78 \%)$ & $36(75 \%)$ \\
\hline Headache & $9(56 \%)$ & $24(75 \%)$ & $33(69 \%)$ \\
\hline Cognitive symptoms & $10(63 \%)$ & $28(88 \%)$ & $38(79 \%)$ \\
\hline Dizziness & $5(31 \%)$ & $19(59 \%)$ & $24(50 \%)$ \\
\hline Vertigo/motion sickness & $3(19 \%)$ & $12(38 \%)$ & $15(31 \%)$ \\
\hline Falling sensation & $3(19 \%)$ & $8(25 \%)$ & $11(23 \%)$ \\
\hline Stinging/burning sensation & $7(44 \%)$ & $14(44 \%)$ & $21(44 \%)$ \\
\hline Previous Bell's palsy (reported by patient) & $1(6 \%)$ & $7(22 \%)$ & $8(17 \%)$ \\
\hline Contact hypersensitivity & $5(31 \%)$ & $7(22 \%)$ & $12(25 \%)$ \\
\hline Sound sensitivity & $6(38 \%)$ & $16(50 \%)$ & $22(46 \%)$ \\
\hline Other hearing symptoms & $8(50 \%)$ & $19(59 \%)$ & $27(56 \%)$ \\
\hline Light sensitivity & $5(31 \%)$ & $10(31 \%)$ & $15(31 \%)$ \\
\hline Other visual symptoms & $7(44 \%)$ & $16(50 \%)$ & $23(48 \%)$ \\
\hline Psychiatric symptoms $^{a}$ & $9(56 \%)$ & $24(75 \%)$ & $33(69 \%)$ \\
\hline Muscular symptoms & $14(88 \%)$ & $26(81 \%)$ & $40(83 \%)$ \\
\hline Arthralgia & $13(81 \%)$ & $27(84 \%)$ & $40(83 \%)$ \\
\hline Back pain & $10(63 \%)$ & $20(63 \%)$ & $30(63 \%)$ \\
\hline Joint stiffness & $10(63 \%)$ & $21(66 \%)$ & $31(65 \%)$ \\
\hline Neck stiffness & $9(56 \%)$ & $22(69 \%)$ & $31(65 \%)$ \\
\hline Joint swelling & $7(44 \%)$ & $12(38 \%)$ & 19 (40\%) \\
\hline Enlarged lymph nodes (reported by patient) & $5(31 \%)$ & $6(19 \%)$ & $11(23 \%)$ \\
\hline Fever (reported by patient) & $2(13 \%)$ & $13(41 \%)$ & $15(31 \%)$ \\
\hline
\end{tabular}

${ }^{a}$ Including depression, anxiety, mood swings and psychotic symptoms 
Table 4 Previous antibiotic treatment in Bartonella-seropositive and Bartonella-seronegative patients

\begin{tabular}{llc}
\hline Antibiotic & $\begin{array}{l}\text { Patients positive for anti-Bartonella spp. IgG antibodies } \\
(n=16)\end{array}$ & $\begin{array}{l}\text { Patients negative for anti- } \\
\text { Bartonella spp. lgG antibodies } \\
(n=32)\end{array}$ \\
\hline Doxycycline & $6(38 \%)$ & $9(28 \%)$ \\
Other macrolide & $0(0 \%)$ & $1(3 \%)$ \\
Phenoxymethylpenicillin & $3(19 \%)$ & $1(3 \%)$ \\
$\begin{array}{l}\text { Beta lactam antibiotics other than phenoxymethylpeni- } \\
\text { cillin }\end{array}$ & $1(6 \%)$ & $1(3 \%)$ \\
Clindamycin & $1(6 \%)$ & $0(0 \%)$ \\
Ciprofloxacin & $0(0 \%)$ & $1(3 \%)$ \\
Total, any antibiotic treatment & $10(63 \%)$ & $11(34 \%)$ \\
\hline
\end{tabular}

\section{Discussion}

Many patients suffer from persistent medically unexplained symptoms, and if these patients have been exposed to ticks, an investigation into possible tick-borne infection may be advisable. Whether Bartonella infection should be included in this investigation has yet to be determined. In the present study of Swedish patients with presumed tick exposure and persistent unexplained symptoms, we demonstrated a slightly higher seroprevalence against $B$. henselae and $B$. quintana than reported in previous studies of healthy blood donors [25, 26]. However, a positive Bartonella serology could not be linked to any specific symptom or to a higher prevalence of any epidemiological risk factor related to tick exposure.

Ticks are considered to be one of the most important vectors in Europe, but infected patients may not always have noted a tick bite [27]. In several studies, PCR assays have demonstrated the presence of Bartonella spp. in ticks (including I. ricinus), both in Europe and the USA $[1,6,12]$. However, in Europe, the prevalence of Bartonella spp. in ticks varies greatly from only $0.6 \%$ in Denmark [28] to $11.8 \%$ in Germany and $38.2 \%$ in France [7]. In Sweden, the presence of Bartonella spp. in ticks has been investigated in two studies: one on 167 ticks [29] collected in central Sweden and the second on 1663 ticks collected in Sweden and the Åland Islands, Finland [30]. Both studies failed to demonstrate Bartonella spp. in the examined ticks.

The seroprevalence of antibodies against Bartonella spp. differs between countries. In Europe, the seroprevalence against $B$. henselae in healthy populations is higher in the central and southern countries, ranging from 19\% in Germany to 23\% in Austria to 57\% in Croatia [31-33]. In Sweden, the seroprevalence against B. henselae is 3\% in orienteers [25], $14 \%$ in drug addicts [34] and $29 \%$ in a homeless population [35], and ranges from 1 to $1.6 \%$ in healthy blood donors $[25,26]$. A high seroprevalence against Bartonella spp. in populations of homeless and addicts is also known from other studies [22, 36, 37]. The present study demonstrated a seroprevalence of $7 \%$ against $B$. henselae, which is higher than that reported previously in Sweden (except for homeless persons), even in persons at high risk of exposure to tick bites (such as orienteers). The prevalence of antibodies against $B$. quintana was $1 \%$ in the current study, which is somewhat higher than previously demonstrated in healthy blood donors $(0.2-0.3 \%)[25,26]$ but lower than in values reported for orienteers (3\%) and a homeless population $(4.2 \%)[25,35]$. One patient in the present study had antibodies against both B. henselae and B. quintana, which may represent cross-reactivity; the cross-reactivity between these species has been shown in other studies to be high $[38,39]$. Unfortunately, information on travel history was missing for many patients so no conclusions could be made on the role of travel on the seroprevalence against Bartonella spp.

The patients included in the present study were all being investigated for possible tick-borne infections. Hence, all had most likely been exposed to ticks to some extent. However, our investigation of the different epidemiological factors associated with tick exposure did not show a higher prevalence of any factor in patients with positive Bartonella serology. Rather, there was a tendency to a higher prevalence of some factors in the group with negative serology; these included, in particular, a higher frequency of gardening, berry picking in forested areas and being on a boat in the archipelago. Also, previous tick bites tended to be more common in the seronegative group, as did possession of a cat. This latter finding was against expectation, as it was expected that the seropositive group would have more contact with cats given that cat scratches are the primary mode of transmission of $B$. henselae to humans [19]. However, one previous serological study of cats in Sweden showed a seroprevalence of $1 \%$ against $B$. henselae [40], and when blood from cats 
was investigated for $B$. henselae with culture or PCR assays the prevalence was $2 \%$ [41].

Co-infections are known to occur both in ticks and humans, including Bartonella spp. [11, 42]. Most patients in our study showed signs of previous exposure to at least one other tick-borne pathogen, with $B$. burgdorferi being the most common. No difference between the two groups was noted for co-infections. As a result of the study design, a high prevalence of exposure to various tick-borne pathogens is not surprising.

Cat-scratch disease is caused by $B$. henselae and usually presents with fever and enlarged lymph nodes. However, atypical symptoms occur in up to $20 \%$ of patients, mostly in adults [19]. Neurological symptoms, such as meningoencephalitis, myelitis and neuroretinitis, have been described in up to $10 \%$ of cases [19], and musculoskeletal manifestations, including myalgia and arthralgia/arthritis, also appear in up to $10 \%$ of patients [43]. An investigation of patients examined by a rheumatologist demonstrated a high Bartonella seroprevalence and a high rate of positive Bartonella PCR in the blood [21]. The symptoms most frequently reported by patients in our study were fatigue, arthralgia, muscular symptoms, sleeping problems and cognitive symptoms. These symptoms were reported at similar frequencies from both seropositive and seronegative patients, with the exception of cognitive symptoms, which were more common in the seronegative group. In our seropositive patients, fatigue was the single most common symptom (frequency 94\%).

\section{Conclusions}

We have demonstrated a somewhat higher seroprevalence of antibodies against $B$. henselae and B. quintana in presumed tick-exposed patients than reported previously in blood donors in Sweden. However, Bartonellaseropositive patients did not have a higher prevalence of epidemiological risk factors associated with tick exposure, nor did they have more tick bites, when compared to Bartonella-seronegative patients from the same study cohort. Symptoms were also the same in both seropositive and seronegative patients. Accordingly, these findings do not add support to ticks being vectors for Bartonella spp. transmission. Why the prevalence of Bartonella antibodies is higher in this population remains to be determined.

\section{Acknowledgements \\ We thank Ester Fridenström for help with collection of patient samples and administrative service.}

\section{Authors' contributions}

All authors contributed to the study design and interpretation of the results. $\mathrm{ME}$ and $\mathrm{CN}$ drafted the original manuscript and then all authors contributed to editing of the final manuscript. All authors read and approved the final manuscript.

\section{Funding}

Open access funding provided by Uppsala University. This study was supported by Uppsala County Council, project Grants 41403, 42309 and 1040311, held by $\mathrm{BO}, \mathrm{KN}$ and $\mathrm{AM}$, respectively.

\section{Availability of data and materials}

Raw data that are not included in the main text can be shared with researchers upon reasonable request.

\section{Declarations}

\section{Ethics approval and consent to participate}

This study was approved by the Swedish Ethical Review Authority, Uppsala, Sweden (reg. no. 2015/249). Informed written consent was obtained from all patients before study enrollment and the investigation conformed to the principles outlined in the latest version (2013) of the Declaration of Helsinki [44].

\section{Consent for publication}

Not applicable.

\section{Competing interests}

The authors declare that they have no competing interests.

\section{Author details}

${ }^{1}$ Department of Medical Sciences, Section of Infectious Diseases, Uppsala University, Uppsala, Sweden. ${ }^{2}$ Department of Medical Sciences, Section of Clinical Microbiology, Uppsala University, Uppsala, Sweden. ${ }^{3}$ Department of Women's and Children's Health, International Maternal and Child Health (IMCH), Uppsala University, Uppsala, Sweden.

Received: 13 June 2021 Accepted: 28 September 2021

Published online: 12 October 2021

\section{References}

1. Müller A, Reiter M, Schötta AM, Stockinger H, Stanek G. Detection of Bartonella spp. in Ixodes ricinus ticks and Bartonella seroprevalence in human populations. Ticks Tick-Borne Dis. 2016;7:763-7.

2. Okaro U, Addisu A, Casanas B, Anderson B. Bartonella species, an emerging cause of blood-culture-negative endocarditis. Clin Microbiol Rev. 2017;30:709-46.

3. Billeter SA, Levy MG, Chomel BB, Breitschwerdt EB. Vector transmission of Bartonella species with emphasis on the potential for tick transmission. Med Vet Entomol. 2008;22:1-15.

4. Regier Y, O'Rourke F, Kempf VAJ. Bartonella spp.-a chance to establish One Health concepts in veterinary and human medicine. Parasit Vectors. 2016:9:261.

5. Cotté V, Bonnet S, Le Rhun D, Le Naour E, Chauvin A, Boulouis H-J, et al. Transmission of Bartonella henselae by Ixodes ricinus. Emerg Infect Dis. 2008;14:1074-80.

6. Telford SR, Wormser GP. Bartonella spp. transmission by ticks not established. Emerg Infect Dis. 2010;16:379-84.

7. Dietrich F, Schmidgen T, Maggi RG, Richter D, Matuschka F-R, Vonthein $\mathrm{R}$, et al. Prevalence of Bartonella henselae and Borrelia burgdorferi sensu lato DNA in Ixodes ricinus ticks in Europe. Appl Environ Microbiol. 2010;76:1395-8.

8. Sanogo YO, Zeaiter Z, Caruso G, Merola F, Shpynov S, Brouqui P, et al. Bartonella henselae in Ixodes ricinus ticks (Acari: Ixodida) removed from humans, Belluno province, Italy. Emerg Infect Dis. 2003;9:329-32.

9. Jaenson TG, Tälleklint L, Lundqvist L, Olsen B, Chirico J, Mejlon H. Geographical distribution, host associations, and vector roles of ticks (Acari: Ixodidae, Argasidae) in Sweden. J Med Entomol. 1994;31:240-56.

10. Piesman J, Gern L. Lyme borreliosis in Europe and North America. Parasitology. 2004:129(Suppl):S191-220.

11. Halos L, Jamal T, Maillard R, Beugnet F, Le Menach A, Boulouis H-J, et al. Evidence of Bartonella sp. in questing adult and nymphal Ixodes ricinus 
ticks from France and co-infection with Borrelia burgdorferi sensu lato and Babesia sp. Vet Res. 2005;36:79-87.

12. Angelakis E, Billeter SA, Breitschwerdt EB, Chomel BB, Raoult D. Potential for tick-borne bartonelloses. Emerg Infect Dis. 2010;16:385-91.

13. Vayssier-Taussat M, Moutailler S, Féménia F, Raymond P, Croce O, La Scola $\mathrm{B}$, et al. Identification of novel zoonotic activity of Bartonella spp., France. Emerg Infect Dis. 2016;22:457-62.

14. Anderson $B E$, Neuman MA. Bartonella spp. as emerging human pathogens. Clin Microbiol Rev. 1997:10:203-19.

15. Angelakis E, Raoult D. Pathogenicity and treatment of Bartonella infections. Int J Antimicrob Agents. 2014;44:16-25.

16. Jacomo V, Kelly PJ, Raoult D. Natural history of Bartonella infections (an exception to Koch's postulate). Clin Diagn Lab Immunol. 2002;9:8-18.

17. Rolain JM, Brouqui P, Koehler JE, Maguina C, Dolan MJ, Raoult D. Recommendations for treatment of human infections caused by Bartonella species. Antimicrob Agents Chemother. 2004:48:1921-33.

18. Maurin M, Birtles R, Raoult D. Current knowledge of Bartonella species. Eur J Clin Microbiol Infect Dis. 1997;16:487-506.

19. Canneti B, Cabo-López I, Puy-Núñez A, García García JC, Cores FJ, Trigo M, et al. Neurological presentations of Bartonella henselae infection. Neurol Sci. 2019;40:261-8.

20. Brinar VV, Habek M. Rare infections mimicking MS. Clin Neurol Neurosurg. 2010;112:625-8.

21. Maggi RG, Mozayeni BR, Pultorak EL, Hegarty BC, Bradley JM, Correa M, et al. Bartonella spp. bacteremia and rheumatic symptoms in patients from Lyme disease-endemic region. Emerg Infect Dis. 2012;18:783-91.

22. Brouqui P, Lascola B, Roux V, Raoult D. Chronic Bartonella quintana bacteremia in homeless patients. N Engl J Med. 1999;340:184-9.

23. Raoult D. Lack of knowledge can anger patients with chronic diseases. Lancet Infect Dis. 2012;12:654-5.

24. Nilsson K, Skoog E, Jones V, Labbé Sandelin L, Björling C, Fridenström E, et al. A comprehensive clinical and laboratory evaluation of 224 patients with persistent symptoms attributed to presumed tick-bite exposure. PloS ONE. 2021;16(3):e0247384.

25. McGill S, Wesslen L, Hjelm E, Holmberg M, Rolf C, Friman G. Serological and epidemiological analysis of the prevalence of Bartonella spp. antibodies in Swedish elite orienteers 1992-93. Scand J Infect Dis. 2001:33:423-8.

26. McGill S, Wesslén L, Hjelm E, Holmberg M, Auvinen MK, Berggren K, et al. Bartonella spp. seroprevalence in healthy Swedish blood donors. Scand J Infect Dis. 2005;37:723-30.

27. Parola P, Raoult D. Ticks and tickborne bacterial diseases in humans: an emerging infectious threat. Clin Infect Dis. 2001;32:897-928.

28. Stensvold CR, Al Marai D, Andersen LO, Krogfelt KA, Jensen JS, Larsen KS, et al. Babesia spp. and other pathogens in ticks recovered from domestic dogs in Denmark. Parasit Vectors. 2015;8:262.

29. La Scola B, Holmberg M, Raoult D. Lack of Bartonella sp. in 167 Ixodes ricinus ticks collected in central Sweden. Scand J Infect Dis. 2004;36:305-6.

30. Cronhjort S, Wilhelmsson P, Karlsson L, Thelaus J, Sjödin A, Forsberg P, et al. The tick-borne diseases STING study: real-time PCR analysis of three emerging tick-borne pathogens in ticks that have bitten humans in different regions of Sweden and the Aland islands. Finland Infect Ecol Epidemiol. 2019;9:1683935.

31. Pandak N, Daković-Rode O, Cabraja I, Kristof Z, Kotarac S. Prevalence of Bartonella henselae antibodies in children and blood donors in Croatia. Infection. 2009:37:166-7.

32. Rath PM, von Recklinghausen G, Ansorg R. Seroprevalence of immunoglobulin $\mathrm{G}$ antibodies to Bartonella henselae in cat owners. Eur J Clin Microbiol Infect Dis. 1997;16:326-7.

33. Skerget M, Wenisch C, Daxboeck F, Krause R, Haberl R, Stuenzner D. Cat or dog ownership and seroprevalence of ehrlichiosis, Q fever, and catscratch disease. Emerg Infect Dis. 2003;9:1337-40.

34. McGill S, Hjelm E, Rajs J, Lindquist O, Friman G. Bartonella spp. antibodies in forensic samples from Swedish heroin addicts. Ann NY Acad Sci. 2003:990:409-13.

35. Ehrenborg C, Byström R, Hjelm E, Friman G, Holmberg M. High Bartonella spp. seroprevalence in a Swedish homeless population but no evidence of trench fever. Scand J Infect Dis. 2008;40:208-15.

36. Jackson LA, Spach DH, Kippen DA, Sugg NK, Regnery RL, Sayers MH, et al. Seroprevalence to Bartonella quintana among patients at a community clinic in downtown Seattle. J Infect Dis. 1996:173:1023-6.

37. Chmielewski T, Podsiadły E, Tylewska-Wierzbanowska S. Presence of Bartonella spp. in various human populations. Pol J Microbiol. 2007;56:33-8.

38. Sander A, Posselt M, Oberle K, Bredt W. Seroprevalence of antibodies to Bartonella henselae in patients with cat scratch disease and in healthy controls: evaluation and comparison of two commercial serological tests. Clin Diagn Lab Immunol. 1998;5:486-90.

39. Dalton MJ, Robinson LE, Cooper J, Regnery RL, Olson JG, Childs JE. Use of Bartonella antigens for serologic diagnosis of cat-scratch disease at a national referral center. Arch Intern Med. 1995;155:1670-6.

40. Hjelm E, McGill S, Blomqvist G. Prevalence of antibodies to Bartonella henselae, B. elizabethae and B. quintana in Swedish domestic cats. Scand J Infect Dis. 2002;34:192-6.

41. Engvall EO, Brändström B, Fermér C, Blomqvist G, Englund L. Prevalence of Bartonella henselae in young, healthy cats in Sweden. Vet Rec. 2003:152:366-9.

42. Regier Y, Komma K, Weigel M, Kraiczy P, Laisi A, Pulliainen AT, et al. Combination of microbiome analysis and serodiagnostics to assess the risk of pathogen transmission by ticks to humans and animals in central Germany. Parasit Vectors. 2019;12:11.

43. Maman E, Bickels J, Ephros M, Paran D, Comaneshter D, Metzkor-Cotter E, et al. Musculoskeletal manifestations of cat scratch disease. Clin Infect Dis. 2007:45:1535-40

44. World Medical Association. World Medical Association Declaration of Helsinki: ethical principles for medical research involving human subjects. JAMA. 2013;310:2191-4.

\section{Publisher's Note}

Springer Nature remains neutral with regard to jurisdictional claims in published maps and institutional affiliations.
Ready to submit your research? Choose BMC and benefit from:

- fast, convenient online submission

- thorough peer review by experienced researchers in your field

- rapid publication on acceptance

- support for research data, including large and complex data types

- gold Open Access which fosters wider collaboration and increased citations

- maximum visibility for your research: over 100M website views per year

At BMC, research is always in progress.

Learn more biomedcentral.com/submissions 